\title{
1 \\ Wired Cities - Opportunities for small and medium sized cities on the Information Highway
}

\author{
R. E. Strauss, D. Schoder, G. Müller \\ Albert-Ludwigs-University Freiburg \\ Institute for Informatics and Society \\ Department of Telematics \\ Friedrichstrasse 50, 79098 Freiburg i. Br. (Germany) \\ \{rstrausslschoder|mueller\}@iig.uni-freiburg.de
}

\section{Keywords}

Wired Cities, Media Community, Technopoles, Science City, City Net, Media Office, Field Study, Electronic Education

\section{WIRED — IN SMALL AND MEDIUM SIZED CITIES?}

Certainly one of the most fascinating developments in a world economy whose basic productive infrastructure is made up of information flows and communication media, are cities and regions becoming the "critical agents" of the economic development. Since regions and cities are more flexible in adapting to changing conditions of markets, technologies and culture, they have a greater response capacity to generate targeted development projects, encourage the growth and innovativeness of small and medium companies and create an overall innovative climate. Within these city developments we can distinguish two separate approaches. On one side "Technopoles" have been established, including various deliberate attempts to plan and promote, within one concentrated area, technologically innovative, industrial-related production as technology parks, science cities and the like. Examples are Silicon Valley (USA), Boston's Highway 128 (MIT, USA) or Sophia-Antipolis (France).[3]

On the other hand, "Wired Cities" indicate a community in which new telecommunication technologies are used to provide all kinds of informations and electronic services to businesses and households. Defined more broadly, nearly any new development in computing and the use of telecommunication media might be called a "Wired City" if used to provide services and business opportunities to businesses and households of a community. These Wired Cities may be a part of these Technopoles, but not necessarily so. The use of modern telecommunication 
media allows to get especially small and medium sized cities on the information highway, since specific contents are quite often available in small and medium sized cities, due to their historic development. The free access and availability of telecommunication media also comfors federal structures and may prevent the development of "suburb nightmares" which can occur in a megalopolis like Los Angeles.

\section{LEARNING THE LESSONS FROM HISTORY}

Over the past years, an enormous number of field studies have been conducted like in Orlando (USA), Kansai Science City (Japan), Tsukuba (Japan), in Germany the Stuttgart, Nuremberg, Berlin, Munich and Leipzig trials or most recently the "Bodensee Mall Project".[2][3][11] Concluding out of these ongoing trials and the sometimes enormous failures in the past, we may be able to address the 9 most critical success factors for the genesis, structure, and outcomes of these attempts (Figure 1).[3]

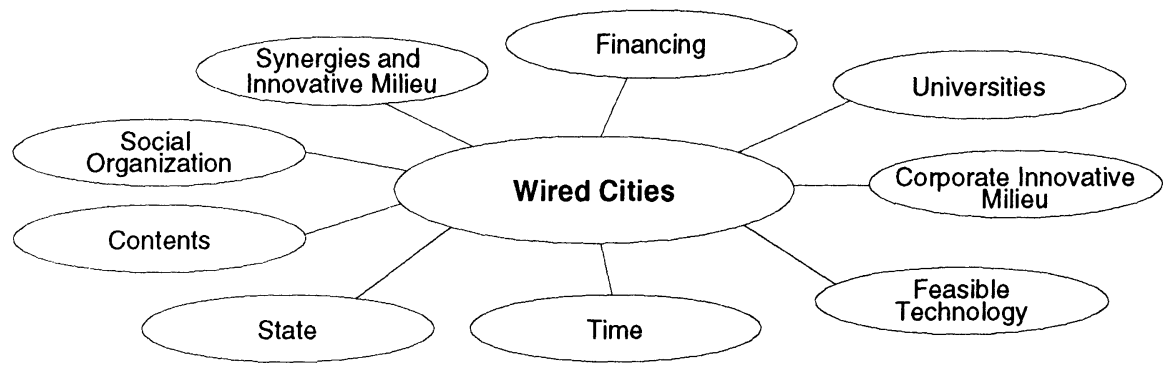

Figure 1: $\quad$ Wired Cities - Key Factors

\section{(1) Synergies and an innovative milieu}

Synergies and an innovative milieu refer to the sense of networks connecting individuals in many different organizations, either public or private, profit or non-profit, large-scale or small scale. Within this network and innovative milieu the free flow of informations, ideas and know how and a particular form of collective learning between the individuals and organizations is encouraged. Synergies and an overall innovative climate lead together with modern telecommunication media most recently to the debate of reinventing processes and procedures, like "Reinventing Government" or even debates on basic informational provision and access to modern telecommunication networks as a basic right in society.[9][6]

\section{(2) Corporate innovative milieu}

Besides an overall innovative milieu also a corporate innovative milieu is urgently needed. This milieu might exist as a private network within one company as the American private corporate model with laboratories right within their premises or the Japanese statist corporate model relating to government and the research in public institutes.[3] Internally, these corporations are forced to faciliate the learning of all its members and continually transform themselves, or in other words, encourage the very promissing "organizational learning". 


\section{(3) State}

The different experiments and field studies point out that the state plays a crucial role, while either intervening in the technological development or accompanying the innovative milieu with legislative or economical frameworks and incentives. Furthermore, the government can mediate its presence by its ability to encourage research and development that could normally not be justified, e.g. through specialised institutions offering venture capital. The direct relationship between the cities and the local, state governments forces the development of agendas not only for specific parts, but for whole geographical (federal) areas.

\section{(4) Universities}

Universities are critical in helping to develop technologies and basic innovations, as well as contribute to the innovative milieu through linkages to industrial and commercial development in the sense of "application oriented institutes". Besides the role to fulfill the generating new (basic and applied) knowledge, universities have to perform training, in both requisite quality and quantity and finally may also support the process of spin-offs of their scientific research into a network of industrial firms and business ventures. In this vein, autonomous universities, based on scholarly quality and academic independence, being linked to industry through a set of formal ties or informal networks, are fundamental in two aspects: for the provision of the new information and technology and the human capital to handle it and contribute to the innovative milieu.

\section{(5) Financing}

For the financing two ways seem to be obvious. First, financing can be provided by the state, state-owned venture capital agencies or local city fundings. Second, the key players may help to finance these projects, not only getting engaged in the technological realisation and the offering of services and contents, but also as financial investors.

\section{(6) Time}

Furthermore, time has to be taken into account. Time is relevant in different levels - as well as in an operative (short-run) as a strategic (long run) orientation. While Wired Cities certainly cannot be operatively build within a short period of time due to restrictions on the side of the main contributing parties and political decision processes, the strategic orientation and planning has to start as soon as possible in order to develop a basic conceptual framework. In the operative sense, all potentially contributing parties should be involved in the setup procedure in working out the agenda.

\section{(7) Feasible technology}

Field studies in Germany or also in Orlando (USA) indicate two important aspects. First, the technologies for a realization of a Wired City have to be available already at the time of the basic, strategic orientation. Political wishful thinking and the unrestricted faith in future technologies often turn the Wired City into a nightmare for the contributing parties. Second, technology cannot be the predominant aspect for the cities, because the development of these necessary technologies never pertains to the disposition of the cities themselves. This aspect is especially true for small and medium sized cities which in general do not have serious command of the technological development. 


\section{(8) Contents}

In this vein, the success depends much more on the programming content but on the physical infrastructure by which the various services are delivered. As the experiences in the various field studies show, the often sophisticated infrastructure alone does not provide anything customers want to spend time with or pay money for. People do not want fiber, switches, set-topboxes, a.s.o., but rather useful information, entertainment, thinks which add to comfortability and time saving. In short, it is not technology it is content and service for which the "average" household is more likely to give money for. Because quality programming and development of differentiated services and contents is expensive and depends extremely on the local institutions and organisations - the innovative climate - breakthroughs in transmission media have a very restricted effect on the viewing patterns and habits than originally predicted.[5] The French videotex system "Minitel" shows that a content-driven approach, along with an excellent technology, may guarrantee the diffusion in the use and the overcoming of "critical masses" in society.[7]

\section{(9) Social acceptability}

Among the factors contributing to social acceptability we find openess to innovation, ease of use of technology, customized to various levels of society, and the (subjective) trust in the correct functionning of the technology, including aspects of privacy and informational selfdetermination. The latter implies problems of data security. Those problems may arise when trying to offer sensitive services on the network, e.g. consulting services concerning personal problems or the verifiable identification of persons within the network. The need arises to generate electronic institutions and means with common, socially learned properties (e.g. digital money which allows for anonymuous paying) which are more likely socially acceptable.

\section{WIRED CITY FREIBURG}

The beginning of the initiative has been triggered by the Ministry of State of Baden-Wuerttemberg (Germany) and the city of Freiburg (200.000 inhabitants), proclaiming that the government wants to promote future prospect industries and activities in the section of "media" and the "information highway".[1] Besides this, the parliament of the state installed worldwide the first "Multimedia-Enquete Commission" in order to promote the development in this field. Three working groups (WG) have been formed in Freiburg due to the requirements of the analytical framework above. Besides the city major and the administration also local industry and university participated. While WG 3 ("Freiburg Demand") concentrated on the possibilities, services, and markets of a wired city, WG 2 ("Infrastructure") dealt with the possible media and networks, the technological costs, the necessary bandwidth, and the possible date of provision within the city. WG 1 ("Education") was established to find answers to the questions how education might help local industry to fulfill their need for qualified employees in this field, as well as how Freiburg with a traditionally strong and well-known university and other educational organizations might deliver educational services nationwide. The social organization and innovative milieu was also supported by the local city development agency (FWT) and the Department of Telematics at the university. 


\subsection{Projects and infrastructure}

\section{Education on and for the Information Highway}

The industry claims a lot of demand for qualified workers in the field of "communication" and "media" in form of a "Media Master". The multitude of requirements has to include all the different communication phases on the new media and has to include didactical abilities as well as the knowledge to serve as an information agent for different target groups and information seekers. This requires technological skills as well as the ability to enrich informations in a multimedial way. Still, the education services have to be adaptive in the reaction to changes of technology or contents.

The development of adequate studies in the city is supported by the pedagogical university (studies for "communication economics", "media pedagogics") to get teachers accquainted with the basic technologies and possibilities of the new media. The university is going to establish a curriculum together with other partner universities in Europe ("European Media Master"). The administration and business academy (VWA) is preparing for a "Media Master" which will be offered nationwide, also in future electronically, as well as the Adult Education Centre (VHS) together with the German Telekom for Telelearning. Besides this, interactive learning programs (Computer Based Training) are developed based on content expertise of the Freiburg region (ecology at the working place, public transport strategies etc.) or private households (e.g. ecology at home). First products like ecological test and informations on CD-ROM, ecological house building or ecological auditing will be provided electronically soon.

\section{Freiburg "Info-Kiosk" and "Info-System"}

The spectrum of possibilities and the implementation for Freiburg in terms of a field study stretches from a relatively simple Freiburg "Info-Kiosk", to Freiburg "Info-System" to the "Freiburg Field Study" in a technically highly equipped new part of the city. This new part offers enormous possibilities through "fiber-to the-home" or ISDN. Firstly, the Freiburg "Info-Kiosk" is able to realize ideas like interactive information station spread all over the city to provide informations about the city, e.g. in form of touristic videos. The aim will be the offer of a broad supply and acceptance, e.g. including tickets for public transport facilities, hotel rooms, city maps, with the option to make reservations directly via the electronic interface. Also regionally interesting informations from Switzerland or France will be included. The financing of this system will be made through advertisements on the outer side of the "Info-Kiosks" or within the interactive programs.

Besides the "Info-Kiosks" a widespread "Freiburg Info-System" will be established. While the "Info-Kiosks" will be at some places in the city connected with fiber-technology, the offer of PC-solutions at central and public points will enrich the informations of the "Info-Kiosks". PC-provided informations will be found at medical offices, pharmacies and other public places like banks. These systems will offer further informations e.g. about nourishment and deseases.

\section{Field study "Rieselfeld"}

The field study conducted in a special new part of the city will integrate a multitude of aspects and requires a concept on several levels. The infrastructure will be based on international standards and technological equipment from major German companies in this field. Services will focus on the existing, widespread available ISDN for services without video, e.g. electronic newspapers, citizen radio, local area TV, childrens TV. An easy access with user-friendly inter- 
faces will be offered, including the provision of informations as well as the communication within this part of the city. The local companies will offer various kinds of multimedia services, especially through the local printing and publishing houses (PPH). A nation-wide delivery of services is already possible via the BelWue Net, the scientific network between the universities. The local printing industry already establishes a regional archive ("Regio-Archive") for informations out of several areas. The costs for the user will be extraordinary low, since the necessary equipment as well as the transmissions costs will be sponsored by private companies.

\section{"Newspaper 2000"}

New business fields are being developed in the field of electronic markets by the local newspapers, e.g. in the electronic delivery of actual daily news (as a news-broker), the offering of research facilities in data bases or as a common service provider (e.g. for the bundling of selected program rubrics, or forums, using various metaphors including mall, digital city etc.). The spectrum of alternative retrieval services can be restricted to the pure offering of the services, where the research work remains with the user, or the provider serves as a service provider in a closer sense, where the user only presents a complete interest profile and the detailed research is fulfilled, e.g. by software agents.

\section{TV Magazines and "Regio-Window"}

The "Media Community" will also possess TV contents. "Interactive TV" or "Video-OnDemand" will not be realized in Freiburg due to their technical and financial demanding properties. The migration towards such services may be of strategic interest. Local newspapers and regional newspapers in Basle (Switzerland) just have started a private cooperation in the TV sector to produce local TV magazines and a "Regio-Window" for the already existing TV networks.

\section{2 "Freiburg Media Office" - operative coordination and strategic plan- ning}

The tasks of the "Freiburg Media Office" are:

- Coordination of educational services and new educational forms.

- Development and continous service of an implementation strategy for the Freiburg field studies.

- Coordination of the field studies and lobbying with the state and the European Commission.

- Moderation between users and supplying companies.

- Coordination of the pilot projects, Community-Marketing.

- Innovator and organizer of the media community.

- Strategic debates on new possibilities and business sectors.

- "Clearing" of the business strategies of the Freiburg media companies.

- Chair for the "Freiburger Media Days".

- Knowledge transfer between education, economy and science.

- Strategical and longterm consultancy and info-services.

- Participation in media-political debates. 
The main problem of a media office is the interdisciplinary and independant coordination and planning of the "Media Community Freiburg". A neutral organizational and personell establishment of the media office, with no administration-overhead, no conflict or competition with existing companies and a modular structure for further developments is required. Besides the coordination the media office should also keep the contact with the network provider, providing a City-Net (Figure 2). A first activity will be the organization of the "1. Freiburg Media Day",

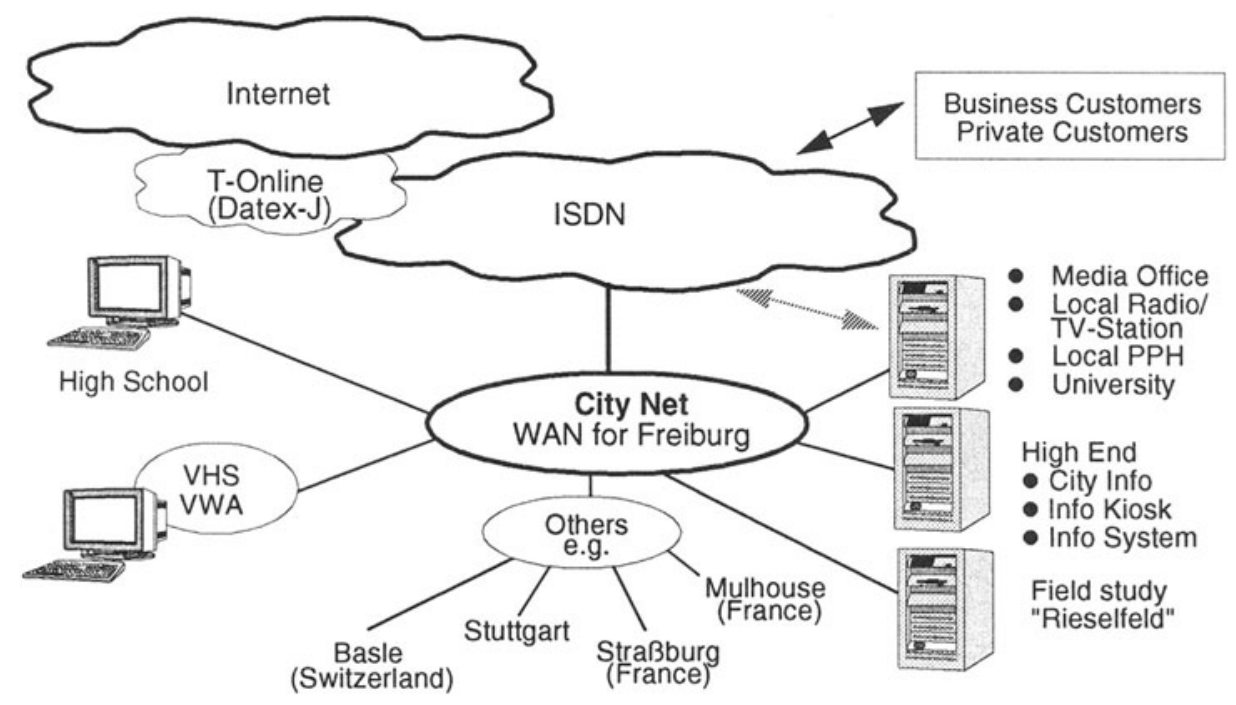

Figure 2: $\quad$ City Net Freiburg

in order to establish Freiburg as a wired city. In the strategic sense a "think-tank" could be established for a systematic scanning of further developments in the field of media and technology.

\subsection{Financing}

The financing of the media office and the field studies will be made very cost efficient, even if the establishment of the media office requires some venture capital. Potential earnings can be used for a further development of the activities and the tasks of the office. The financing will be spread in several parts: (1) Infrastructure can be obtained elsewhere, summing up to a value of 1.5 Mio DM/year for 3 years; (2) The Media Office will first be financed through the city of Freiburg. This office first requires 3 persons incl. administrative staff, equalling to DM 300.000 for personell. Due to the commitment of the Freiburg industry, which will give further employees out of their own business into the media office, a team with $8-10$ persons can be formed. Office space provided by the city council are available at no expense. The media office has to connect and integrate the field study into other field studies and take care for the acquisition of further money from the state, private companies, equipment from hardware providers, and the contact to European financing initiatives. After a time of 3 years the media office has to 
finance itself autonomously through consultancy, projects, or else. (3) The development of possible services and content will remain with the existing companies in the city. (4) The field study will be financed with sponsoring through advertisements. There are commitments by companies to sponsor the field studies e.g. through advertising.

\section{Acknowledgements}

This article was supported by the City Hall, Rolf Böhme (major of the city of Freiburg), Peter Wagner (Freiburg Wirtschaft und Touristik, FWT), Edgar Faller (Deutsche Telekom Freiburg) and several local companies. Thanks are also due to Rob Kling (University of California at Irvine, USA), the colleagues of ATR Laboratories (Kyoto, Japan) who participated in the discussion on Wired Cities and finally the chair of the IFIP'96 World Computer Congress/IT Tools in Canberra, Dr. Nobuyoshi Terashima, for this invited speech.

\section{References}

[1] Böhme, R.: Medienstandort Freiburg, in: SuperHighway, Vol. 5 (1995), No. 7, p. 26.

[2] Brenner, W.; Kolbe, L.: The German Infobahn Trials To Reach the Home - A Comparative Study, in: Dholakia, R. R.; Fortin, D. (eds.): Living and Working in Cyberspace: New Information Technologies at Home and at Work - Opportunities, Strategies and Policy Issues, Proceedings of the 1995 Conference on Telecommunications and Information Markets, Newport (USA) 1995, pp. 2 - 10.

[3] Castells, M.; Hall, P.: Technopoles of the World. The Making of the 21st Century Industrial Complexes, London: Routledge, 1994.

[4] Dutton, W. H.; Blumler, J. G.; Kraemer, K. L.: Continuity and Change in Conceptions of the Wired City, in: Dutton, W. H.; Blumler, J. G.; Kraemer, K. L. (eds.): Wired Cities. Shaping the Future on Communications, Boston: G. K. Hall, 1986, pp. 3 - 26.

[5] King, J. L.: Points of Conclusion and Comparison, in: Dutton, W. H.; Blumler, J. G.; Kraemer, K. L. (eds.): Wired Cities. Shaping the Future on Communications, Boston: G. K. Hall, 1986, pp. 409 - 419.

[6] Osborne, D.; Gaebler, T.: Reinventing Government; How the Entrepreneurial Spirit is Transforming the Public Sector, Reading (Mass.): Addison-Wesley, 1992.

[7] Schoder, D.: Erfolg und Mißerfolg telematischer Innovationen - Erklärung der „Kritischen Masse" und weiterer Diffusionsphänomene, Wiesbaden: Gabler, 1995.

[8] Strauss, R. E.; Padovan, B.; Schoder, D.: Service Providers in Electronic Markets - Transformations in the Printing and Publishing Sector, in: Dholakia, R. R.; Fortin, D. (Hrsg.): Living and Working in Cyberspace: New Information Technologies at Home and at Work - Opportunities, Strategies and Policy Issues, Newport (USA) 1995, pp. 144 - 151.

[9] Wigand, R. T.: The National Policy Context, in: Dutton, W. H.; Blumler, J. G.; Kraemer, K. L. (eds.): Wired Cities. Shaping the Future on Communications, Boston: G. K. Hall, 1986, pp. 287 - 302.

[10] Zimmermann, H.-D.: The Electronic Mall Bodensee: A Virtual Marketplace for Private and Commercial Customers, in: Dholakia, R. R.; Fortin, D. (Hrsg.): Living and Working in Cyberspace: New Information Technologies at Home and at Work - Opportunities, Strategies and Policy Issues, Newport (USA) 1995, pp. 11 - 17. 